\title{
A INTERPRETAÇÃO SIMULTÂNEA NO CONTEXTO POLÍTICO
}

\author{
Flávia Medeiros Álvaro Machado* \\ Universidade de Caxias do Sul
}

Heloísa Pedroso de Moraes Feltes**

Universidade de Caxias do Sul

\begin{abstract}
Resumo: Este artigo tem como foco as práticas interpretativas simultâneas e as possibilidades semântico-pragmáticas relacionadas às escolhas linguísticas (lexemáticas) dos discursos na ordem política das Casas Legislativas em que atuam o tradutor-intérprete de Libras e Português (TILSP). Uma análise ilustrativa é realizada a partir de um corpus constituído de transcrições, da fala de um parlamentar e da interpretação simultânea pelo TILSP em uma Sessão Ordinária da Tribuna Livre da Câmara Municipal de Pelotas, Rio Grande do Sul. Para isso, utilizou-se o software ELAN. Analisam-se as escolhas linguísticas do TILSP, no ato interpretativo, de expressões e terminologias no contexto político. O objetivo foi o de discutir algumas competências e habilidades que o TILSP deve desenvolver para a prática nesse contexto específico (e.g. HURTADO ALBIR, 1999). Palavras-chave: Contexto Político. Interpretação Simultânea. Competência Tradutória.
\end{abstract}

\footnotetext{
* Doutoranda em Letras (UCS/UniRitter); Mestre em Letras, Cultura e Regionalidade (UCS); Docente e tradutora e intérprete de Libras e Português pelo Programa de Libras (PLIBRAS) da Universidade de Caxias do Sul (UCS). Caxias do Sul, Rio Grande do Sul, Brasil. E-mail: ils.flaviamachado.ils@gmail.com

** Doutora em Linguística (PUC-RS). Orientadora, docente e pesquisadora pelo Programa de Stricto Sensu do Mestrado em Letras, Cultura e Regionalidade (UCS) e do Doutorado em Letras da Universidade de Caxias do Sul (UCS/UniRitter). Caxias do Sul, Rio Grande do Sul, Brasil. E-mail: helocogn@terra.com.br
} 


\title{
SIMULTANEOUS INTERPRETING IN THE POLITICAL CONTEXT
}

\begin{abstract}
This paper focuses on the simultaneous interpretative practices and the semantic and pragmatic possibilities related to linguistic choices (lexematic) of the discourse in the political order of the Legislative Houses in which the translator-interpreter Libras and Portuguese (TILSP) works. An illustrative analysis is performed from a constituted body of transcripts of: the speech of a parliamentary and a simultaneous interpretation of a TILSP during an Ordinary Session at the Free Tribune of the Municipality of Pelotas, Rio Grande do Sul. For that, we used the ELAN software. We analyzed linguistic choices, on the interpretive act, expressions and terminology in the political context. The purpose was to discuss some competencies and abilities that the TILSP should develop in order to practice that specific context (e.g. HURTADO ALBIR, 1999).
\end{abstract}

Keywords: Political context. Simultaneous Interpretation. Cognitive Semantics.

\section{Introdução}

A demanda sobre a área da atuação dos Tradutores-intérpretes de Libras e Português (TILSP) encontra-se em expansão nesse mercado de trabalho. Em função disso, as competências tradutória e interpretativa são consideradas um elemento chave para a formação do TILSP, uma vez que essas competências dão relevo aos fatores linguísticos e culturais que norteiam essa prática.

No modelo holístico do grupo de pesquisa PACTE³ (apud HURTADO ALBIR, 2005), a "competência tradutória" é um sistema subjacente de conhecimentos, habilidades e atitudes necessárias para traduzir. Ou seja, trata-se de "conhecimentos especializados", compostos por "conhecimentos declarativos e operacionais", que compreendem cinco subcompetências, que vão além dos componentes psicofisiológicos: a bilíngue, a extralinguística, a instrumental, a estratégica e a de conhecimentos sobre a tradução e interpretação.

De acordo com Hurtado Albir (2005), a competência tradutória trabalha diretamente na "subcompetência bilíngue", no que diz res- 
peito ao conhecimento necessário para a comunicação entre duas línguas. Todo tradutor e intérprete adquire essa competência ao longo da formação e durante toda a atuação profissional. É importante destacar que essa competência tradutória e interpretativa também engloba conhecimentos pragmáticos, sociolinguísticos, textuais e gramaticais.

É fundamental para a formação dos tradutores-intérpretes o "conhecimento teórico e especializado", porque é necessário que todo tradutor e intérprete tenha também a capacidade de gerenciar sua atuação, bem como manter o controle emocional e psíquico quando estiver numa atuação simultânea.

A divisão dos conhecimentos em relação à "subcompetência bilíngue" imbrica-se com os processos interpretativos. Identificar o sentido de uma determinada "palavra" sempre requererá do usuário (leitor) a compreensão semântico-pragmática, pois, dependendo do contexto comunicacional, a atuação do tradutor e intérprete ultrapassará o conhecimento teórico e especializado, conduzindo, também, ao conhecimento sociolinguístico. É necessário que o tradutor e intérprete observe a situação sócio-histórica em que será realizado o trabalho.

Retomando as demais subcompetências de Hurtado Albir (2005), considera-se de extrema relevância para o processo da "interpretação simultânea" a (i) Subcompetência Extralinguística - que remete ao conhecimento enciclopédico ${ }^{4}$ e cultural de ambas línguas; a (ii) Subcompetência Instrumental - que abrange o conhecimento das fontes de documentação e dos recursos tecnológicos, como fontes de busca, bases de dados, programas de memórias de tradução e entre outros; e a (iii) Subcompetência Estratégica que faz parte dos conhecimentos necessários para a realização da interpretação e administração de problemas possíveis de serem encontrados durfante o processo da tradução ou interpretação. Esses conhecimentos são necessários para a operacionalização da atividade de tradução e interpretação.

Os "conhecimentos teóricos e práticos" sobre a tradução e interpretação implicam tanto no conhecimento das principais noções 
relativas ao processo interpretativo, como no das estruturas de ambas as línguas em seus diferentes níveis, de modo a promover escolhas interpretativas congruentes. $\mathrm{O}$ processo interpretativo simultâneo envolve componentes psicofisiológicos que se conectam diretamente com aspectos cognitivos, como a memória, a atenção, a organização e a capacidade de análises e sínteses, direcionada ao desempenho dos tradutores-intérpretes.

Os profissionais que atuam como TILSP vêm sendo inseridos nos mais diversos contextos na sociedade. Essa iniciativa se deve à legislação vigente do País, com o propósito de levar as instituições a cumprirem a inclusão social da acessibilidade comunicacional. Com isso, os espaços educacionais não são suficientes para a garantia plena da inclusão do sujeito surdo. É importante que os espaços sociais (públicos) sejam também contemplados na inclusão social da pessoa surda, garantido o acesso à comunicação e à informação nesses espaços. Nesse sentido, os TILSP têm atuado, também, em contexto político, e muitos atuam com a formação em nível de capacitação (extensão). Porém, um curso de extensão não permite uma formação que dê suporte para uma atuação nesse contexto político. Por outro lado, não há instituições no Brasil que habilitem os TILSP para atuações específicas nas áreas educacional, jurídico/ legal, médica/saúde. Portanto, refletir sobre as competências tradutórias e interpretativas nos permite planejar ações que orientarão as futuras formações que habilitem o TILSP nos contextos acima mencionados. O Decreto de $n^{0} 5.626 / 2005$ estabelece apenas que:

Art. 17. A formação do tradutor e intérprete de Libras Língua Portuguesa deve efetivar-se por meio de curso superior de Tradução e Interpretação, com habilitação em Libras - Língua Portuguesa. Art. 18. Nos próximos dez anos, a partir da publicação deste Decreto, a formação de tradutor e intérprete de Libras - Língua Portuguesa, em nível médio, deve ser realizada por meio de: I - cursos de educação profissional; II - cursos de extensão universitária; e III - cursos de formação continuada promovidos por instituições de en- 
sino superior e instituições credenciadas por secretarias de educação.

Tendo como pano de fundo esse cenário e a afirmação de Sacks (2002) de que a sociedade ainda desconhece a funcionalidade do TILSP nos mais diversos contextos de atuação, neste artigo as reflexões partem das escolhas interpretativas que os TILSP realizaram no contexto político das Sessões Ordinárias em Casas Legislativas. Especificamente, a intenção é trazer a problemática que envolve na complexidade das interpretações simultâneas e as ocorrências lexemáticas realizadas durante a pauta da Ordem do Dia5 do Grande Expediente das Sessões Ordinárias da Câmara Municipal de Pelotas.

Salienta-se que o foco deste artigo são os processos da interpretação simultânea do Português para Libras, em contexto político. O objetivo é oferecer uma análise preliminar do processo da interpretação simultânea, a partir de um breve recorte de um corpus de pesquisa maior, na qual se focalizam as escolhas lexemáticas do TILSP em relação aos processos de linguagem, com um olhar mais atento ao uso de terminologias políticas da LP (Língua Portuguesa) para Libras. A partir disso, levanta-se um conjunto de competências especializadas que o TILSP necessita desenvolver para um bom êxito no processo simultâneo da interpretação. É notório que até mesmo as pessoas ouvintes, sem inserção na área política desconhecem termos de que os parlamentares se apropriam. Esses termos são problemáticos em termos intralinguísticos em algum grau semântico-pragmático. Nesse sentido, o TILSP necessita realizar com precisão as suas escolhas interpretativas de uma língua de modalidade oral-auditiva (LP), para uma versão de modalidade gesto-visual (Libras).

Segundo Alves (2005, p. 109), o desempenho dos tradutores-intérpretes vêm ao encontro de reflexões "entre o ritmo cognitivos na produção textual [gesto-visual] de tradutores novatos e experientes e seus respectivos níveis de meta-reflexão e experiência”. Há, no processo de tradução e interpretação de LP para Libras, variáveis 
específicas e muitas dessas estão sob a investigação empírica de desenhos experimentais:

[...] (i) o tipo de texto utilizado; (ii) o perfil dos tradutores - experientes, novatos, bilíngues; (iii) aspectos estratégicos, tais como o uso de fontes de consulta, a solução de problemas e processos de tomada de decisão; (iv) condições de produção, quais sejam, informações sobre especificidades da tarefa de tradução (brief), o públicoalvo e restrições mercadológicas; e (v) aspectos cognitivos, como pressão do tempo, e o papel da memória e de outros mecanismos de apoio interno, por exemplo, processos inferenciais. (ALVES, 2005, p. 110).

Hurtado Albir (2005, p. 110 e 111) considera problemático apropriar-se apenas de uma única avaliação, como instrumentos de desenhos experimentais. Ele acredita que é possível também mapear os distintos "ritmos cognitivos" dos tradutores-intérpretes, observando os "diferentes graus de gerenciamento" do processo de tradução e interpretação.

Dessa maneira, compreende-se que há certas expressões ou termos que possam ser problemáticos para o TILSP no momento que interpreta de uma língua para outra, principalmente quando se trata de conceitos em contexto político. Para Alves (2005), o "ritmo cognitivo" recorre previamente a uma análise textual de ambas línguas a serem trabalhadas. Esse processo permite uma organização hierárquica do processamento cognitivo (sentido variável), no que se refere ao ato simultâneo da interpretação da LP para Libras em diferentes contextos.

Hurtado Albir (1999) discorre sobre o desenvolvimento da competência do tradutor e estabelece que a "competência tradutória", enquanto conhecimento especializado, envolve aspectos textuais, comunicativas e cognitivos. A partir de uma abordagem integralizadora, o processo tradutório é construído por meio de uma pro- 
posta sócio-construtivista, focando em unidades didáticas que aprimoram a prática tradutória e interpretativa do TILSP.

Na sequência, Hurtado Albir (2005) se debruça sobre os estudos que focam a "aquisição da competência tradutória" em relação aos aspectos teóricos e práticos. A autora ressalta que

[e]mbora qualquer falante bilíngue possua competência comunicativa nas línguas que domina, nem todo bilíngue possui competência tradutória. A competência tradutória é um conhecimento especializado, integrando por um conjunto de conhecimentos e habilidades, que singulariza o tradutor e o diferencia de outros falantes bilíngues não tradutores. (HURTADO ALBIR, 2005, p. 19).

Ainda há poucas pesquisas que procuram explorar a "competência tradutória”, mas acredita-se que "[a] aquisição da competência tradutória seria um processo de automatização gradual e de reflexão crítica sobre as próprias intuições" (HURTADO ALBIR, 2005, p. 26). Assim, compreende-se que, à medida que o TILSP for avançando em sua prática, o mesmo adquirirá o "conhecimento especializado" e suas habilidades passarão a aumentar. O tradutor e intérprete numa ação atitudinal passa a "conhecer os traços situacionais", conseguindo definir com mais precisão as estratégias de competências e habilidades de que necessita para a atuação em situações controladas e espontâneas.

Os aspectos linguísticos da tradução e interpretação no âmbito do uso das terminologias usuais no contexto político situam-se diretamente no plano interlingual (JAKOBSON, 1975), pois o TILSP, numa ação de interpretação simultânea parte do léxico da LP para Libras. Recapitulando o entendimento, algumas das estratégias do plano interlinguístico surgem pelo preparo e pelas fontes que auxiliam todo o processo da tradução e interpretação.

Dessa maneira, pensa-se como Evans (2009), que esclarece que não é adequado separar o "significado do contexto", pois poderão 
ocorrer equívocos no entendimento do enunciado que está sendo traduzido ou interpretado. Ou seja, transpondo essa afirmação para a atuação do TILSP, este necessita apropriar-se da "noção inicial dos diferentes tipos de contextos" (p. 13), estreitando os sentidos que as palavras apresentam e, naturalmente, entendendo a noção de "contexto" como um fenômeno complexo e multifacetado, para o uso da língua, em sua compreensão. É nesse sentido que os TILSP devem se apropriar de uma rede de significados, tendo o "conhecimento especializado" que, por sua vez, necessita de uma formação específica que os capacite para o contexto de ordem política, foco do presente estudo.

Os dicionários terminológicos, por exemplo, permitem entender os sentidos usuais de cada lexema. De alguma maneira, o TILSP necessita sempre lançar mão de recursos que ampliem o conhecimento especializado, o qual lhe permitirá estabelecer relações entre experiências prévias com as ocorrências lexemáticas na LP, mesmo tendo que realizar, em frações de segundos, escolhas de sinais manuais numa ação de interpretação simultânea para Libras. Nesse viés, evidencia-se ainda mais a necessidade de analisar a atuação dos TILSP no contexto de ordem política, principalmente por se tratar de contexto que faz uso de terminologias carregadas de conceitos altamente abstratos para ambas as línguas (Libras e Português).

\section{Os profissionais tradutores e intérpretes de Libras e Português: competências e habilidades}

As escolhas que os TILSP realizam durante a construção sintático-semântico-pragmática dos enunciados proferidos na modalidade oral da LP e, ao mesmo tempo, interpretados simultaneamente para Libras, são o ponto de partida para a reflexão sobre as possibilidades de uma formação mais específica nas áreas jurídica e política.

A legislação vigente sobre a Libras no território Nacional se encontra no reconhecimento de seu uso como língua natural da co- 
munidade surda, de acordo com o disposto na Lei de $n^{0} 10.436$ de 24 de abril de 2002. Essa Lei foi regulamentada pelo Decreto de $\mathrm{n}^{\mathrm{o}}$ 5.626 de 22 de dezembro de 2005, que normatiza os critérios básicos para a formação do TILSP e entre outros direitos aos surdos.

O Decreto 5.626/2005 é endossado pelo poder público, dando garantia de acesso à comunicação, educação e informação dos sujeitos surdos. Como já destacado na sessão anterior, o Artigo $19^{\circ}$ apresenta subsídios para iniciativas de formação de tradutores e intérpretes de Libras e LP.

A atuação do TILSP em diferentes contextos deve ser o ponto de partida para que se promovam formações que atendam não apenas à interpretação educacional, como também às interpretações comunitárias, consolidando os espaços sociais que acessibilizam a comunicação ao sujeito surdo. Para isso, qualificar e habilitar esses serviços prestados por TILSP é fundamental, preservando o perfil de atuação dos TILSP nesses serviços especializados como

[...] profissional ouvinte, de nível superior, com competência e fluência em Libras para realizar a interpretação das duas línguas, de maneira simultânea e consecutiva, e com aprovação em exame de proficiência, promovido pelo Ministério da Educação, para atuação em instituições de ensino médio e de educação superior; [...] profissional ouvinte, de nível médio, com competência e fluência em Libras para realizar a interpretação das duas línguas, de maneira simultânea e consecutiva, e com aprovação em exame de proficiência, promovido pelo Ministério da Educação, para atuação no ensino fundamental; [...] profissional Surdo, com competência para realizar a interpretação de línguas de sinais de outros países para a Libras, para atuação em cursos e eventos. (Artigo $19^{\circ}$, Decreto $n^{\circ}$ 5.626/2005).

A presença dos TILSP permite à comunidade dos surdos o acesso à comunicação, à informação e à educação, contemplando o direto pelos cidadãos de igual forma e respeitando, assim, as defi- 
ciências auditivas, na garantia dos direitos civil, político e social. Isso permite ao sujeito surdo o exercício da plena cidadania com liberdade e autonomia na sociedade.

$\mathrm{O}$ ato de traduzir e interpretar em duas línguas distintas é compreendido etimologicamente, para alguns autores (JAKOBSON, 1975; RÓNAI, 1976; BASSNET, 2003; ARROJO, 2007; OUSTINOFF, 2011; ECO 2011), como o ato comunicacional de "conduzir, transferir, transpor, trasladar, revelar, explanar, representar, simbolizar" de uma língua para outra.

Entende-se que o ato de traduzir e interpretar de uma língua para a outra envolve escolhas tradutórias e/ou interpretativas corroborando com a visão adotada por Rónai (1976) e sendo essa reforçada por Bassnett (2005, p. 9), de que a tradução não é somente uma transferência de palavras de uma língua para a outra, mas um processo de negociação entre as línguas de uso e a cultura da comunidade linguística. Muitas são as implicações durante o ato de traduzir e interpretar, bem como as possibilidades diversas de identificar os signos verbais e não-verbais de um referido sistema linguístico. Dessa maneira, considera-se um equívoco pensar que a substituição das palavras da LP por sinais manuais em Libras é o suficiente para o desempenho do TILSP.

Nessa ação, é necessário que, durante um ato interpretativo simultâneo, o TILSP se aproprie de vários sentidos semântico-pragmáticos (ocorrências polissêmicas), bem como de terminologias especializadas de ambas as línguas. Para Machado (2012, p. 98), os "[TILSP] fazem escolhas de lexemas manuais que são considerados, naquele momento, os mais apropriados para sua interpretação [simultânea]".

Conforme Quadros (2002, p. 11), o TILSP é uma “pessoa que traduz e interpreta a língua de sinais para a língua falada e vice-versa em quaisquer modalidades que se apresentar (oral ou escrita)". Tanto o conceito de tradução, bem como o conceito de interpretação são ações que compreendem: (a) tradução da Libras para a modalidade escrita do português (competência tradutória); e (b) interpretação simultaneamente da Libras para a modalidade oral do 
português ou da LP para a modalidade gesto-visual (competência interpretativa).

Nos Estudos da Tradução a "interpretação simultânea" realizase sobre equivalências lexemáticas e, com isso, em todos os atos tradutórios e/ou interpretativos, o enunciado dependerá sempre de estratégias linguísticas e tradutórias, bem como de um repertório de conhecimentos enciclopédicos e especializados em cada atuação, de forma a permitir ao TILSP realizar, durante a interpretação simultânea, as escolhas mais próximas para a língua meta. Nesse sentido, é recomendado que o TILSP realize uma análise textual, obtendo um conhecimento prévio da língua fonte (LF), antevendose para o ato interpretativo simultâneo das escolhas lexemáticas que conduzirá para a língua meta.

Com Dascal (2006), compreende-se que interpretar consiste em encontrar "pistas" de significados implícitos, atentando para a polissemia dos itens lexicais que expressam, também, em nosso entendimento, conceitos abstratos com alta complexidade para a interpretação de um enunciado, mesmo quando expresso num contexto linguístico-situacional específico.

É compreensível que no ato simultâneo da interpretação das Sessões Parlamentares, os TILSP se deparem com conceitos altamente abstratos, ou seja, conceitos com alto teor polissêmico, encontrados no contexto de ordem política, pois nesse espaço é comum parlamentares fazerem uso de terminológicas jurídica.

Para o TILSP é, de fato, um desafio atuar no contexto político (com usos terminológicos de cunho jurídico), considerando que certos conceitos estão além do seu conhecimento empírico. Atualmente, é emergente a contratação de TILSP em todos os setores sociais, principalmente no contexto público, ou seja, há uma obrigatoriedade de que as empresas públicas e privadas contratem os TILSP para atuarem nas áreas da educação, médica/saúde, como também no contexto de ordem política. O TILSP é um profissional que "atua na fronteira entre os sentidos da língua de origem, para a língua alvo, com os processos de interpretação relacionando-se com o contexto no qual o signo é formado." (LACERDA, 2010, p. 8). 
Os maiores problemas que os TILSP têm revelado em seus discursos é a falta de equivalências linguísticas e culturais quando interpretam do português para a Libras. Além disso, eles muitas vezes não compreendem suas próprias escolhas e acabam sendo apenas 'reprodutores' da LF (Língua Fonte) para a LM (Língua Meta) Ou seja, por desconhecerem o teor do assunto (conhecimento especializado), que será interpretado, surgem lexemas que são realizados, mas que nem sempre são compreendidos em seus sentidos pelo TILSP. Muitos deles relatam que se sentem despreparados para a atuação no contexto político das Casas Legislativas. Esse fato é compreensível à medida que novas competências e habilidades emergem em função de novos contextos que surgem para a atuação desse profissional.

Nesse cenário, destaca-se a importância dos TILSP estarem em formação continuada, no intuito de aprimorar o ritmo processual cognitivo e contextuais, gerenciando as competências multifacetadas que estão implicadas em diferentes contextos de atuação.

Os TILSP que adquirem o "conhecimento especializado" e o "conhecimento prévio" do enunciado realizam com propriedades o processo interpretativo simultâneo, e suas escolhas lexemáticas se evidenciam num trabalho mais refinado e minucioso durante a atuação desse profissional.

As escolhas interpretativas significam que a tradução e interpretação "envolve muito mais do que a simples troca de itens lexicais e gramaticais entre as línguas e, como pode ser visto na tradução de expressões idiomáticas, [metafóricas/metonímicas], o processo pode incluir a eliminação de elementos linguísticos essenciais do texto em LF [...]" (BASSNETT, 2005, p. 47).

Dessa maneira, o TILSP necessita estar atento e exercitando seu ritmo cognitivo (ALVES, 2005) para os conceitos especializados que deverá interpretar, realizando, assim, de forma apropriada, as escolhas interpretativas recebidas pelo retrospecto audito da LF (LP) e, em seguida, selecionar cognitivamente escolhas lexemáticas para a LM (Libras). 
De acordo com Silva (2006, p. 59), a polissemia é “[...] uma rede de sentidos flexíveis, adaptáveis ao contexto e abertos à mudança". O sentido do significado para o autor

não é estático[,] mas dinâmico, não é dado mas construído no conhecimento enciclopédico e configurado em feixes de conhecimento ou domínios, não é platônico mas corporizado, encarnado nas necessidades, nos interesses e nas experiências dos indivíduos e das culturas. (SILVA, 2006, p. 59-60).

No entanto, ao se entender que as palavras podem ser traduzidas no sentido literal, não há um processo de contextualização do sentido próprio para a situação de comunicação. Essa é uma problemática entre os novatos da área e muitas das vezes surgem equívocos na interpretação simultânea.

$\mathrm{O}$ ato interpretativo simultâneo implica em complexas operações cerebrais, pois envolve uma variedade de circuitos. A prática dos TILSP envolve várias competências e habilidades, algumas bem específicas, que podem ser compreendidas e desenvolvidas a partir das contribuições da Linguística Cognitiva (Semântica Cognitiva). Entre elas, estão as escolhas lexemáticas dos processos da interpretação simultânea com o foco nos conceitos abstratos do contexto político, implicado aos processos interpretativos da Língua Portuguesa (modalidade oral) para a Libras (modalidade gesto-visual).

\section{Múltiplos Sentidos: Semântica e Cognição}

Em Linguística Cognitiva, a polissemia ganha sistematicidade em seu estudo, passando a ser analisada pelos ângulos biológico, psicológico e cognitivo e sociológico. Silva (2006) demonstra a importância da polissemia e sua reintrodução aos estudos da Linguística Cognitiva. A polissemia começa a figurar, então, como 
o resultado da inovação semântica e ocorre por meio da extensão e da restrição de sentido, da metáfora, da metonímia e do uso por diferentes grupos sociais. O critério etimológico e/ou outros critérios que tentam colaborar para a distinção entre polissemia e homonímia são da classe gramatical e da diferença semântica. Segundo Geeraerts (1993 apud SILVA, 2003, p. 94), a distinção entre polissemia e vagueza envolve saber se estamos diante de dois sentidos diferentes ou de duas especificações contextuais de um mesmo sentido (e, portanto, pragmáticas). O exemplo do verbo "deixar", citado por Silva (2003, p. 94), revela os múltiplos sentidos que o verbo é construindo numa sentença. No uso espacial, o verbo tem o significado de "ir embora, retirar-se", como no enunciado " $O$ Zé deixou a sala, quando ela entrou”. Porém, no uso funcional do significado "abandonar" o verbo é aplicado com outro sentido, a exemplo do enunciado "O Zé deixou sua mulher/ emprego".

Silva (2003, p. 95) esclarece que "[...] um uso que esteja convencionalizado constituirá um sentido diferente e fará parte do léxico mental". Observe-se o exemplo do conceito abstrato AUTONOMIA, amplamente analisado em Machado (2012, p. 136):

\begin{abstract}
AUTONOMIA - ("execução de diretrizes e normas") = (s.f.) Livre: faculdade de governar suas próprias leis; AUTONOMIA $_{2}$ - ("planejamento familiar e social") = (s.f.) Livre: faculdade de reger-se por leis próprias; de se governar por si mesmo; AUTONOMIA - ("pedagogia [...] implicada nas ações") $=$ (s.f.) Liberdade: ensinar a pensar certo; AUTONOMIA 4 - ("professor que exerce [...] estratégias") $=($ s.f.) Liberdade: conquista que se alcança na medida em que se luta pela libertação de si, do outro e do mundo; AUTONOMIA 5 - ("alunos [...] nos diferentes espaços sociais") = (s.f.) Independência: faculdade de cada um se decidir ou agir segundo a própria determinação.
\end{abstract}

Atente-se para o fato de que, apesar de AUTONOMIA e AUTONOMIA 2 remeterem à ideia de LIVRE, estes se aplicam dife- 
rentemente no âmbito de "legislação" e de "planejamento". Da mesma forma, AUTONOMIA 3 e AUTONOMIA 4 remetem à ideia de LIBERDADE, mas também se aplicam diferentemente à "pedagogia” e ao "professor”. Para Delbecque (2008, p. 49), “[a] língua nos ajuda a categorizar as experiências que a vida nos proporciona. A resposta à questão de saber aquilo que há nas palavras poderia ser muito simples: o universo inteiro ou, pelo menos, o conjunto das experiências categorizadas linguisticamente". Dessa forma, o significado da palavra

é uma dada forma que simboliza ou substituiu um conceito (ou significado) e esse conceito está ligado a um conjunto de entidades pertencente ao mundo de experiências vividas e das ideias. A relação entre esses três elementos (forma, conceito (ou significado) e referente (ou entidade) constitui o triângulo semiótico [...]”. (DELBECQUE, 2008, p. 52).

A prototipização e a polissemização são a resposta às três tendências funcionais do sistema cognitivo humano. O sistema cognitivo determina a "densidade informativa, propiciando a formação de categorias com muita informação e pouco esforço cognitivo", como também a "flexibilidade, tornando as categorias adaptáveis a novas condições ou realidades do mundo e a novas necessidades expressivas dos falantes" e, por fim, a "estabilidade estrutural, garantindo a permanência das categorias já formadas e a sua utilização na apreensão da mudança." (SILVA, 2010, p. 360).

Assim, a coerência semântica para o conceito AUTONOMIA, citado anteriormente, remete às capacidades cognitivas gerais, ou seja, a linguagem categoriza o mundo de forma natural e por meio de experiências individuais. Nesse contexto, Silva (2003, p. 102103) argumenta que

[a] categorização linguística é, por conseguinte, o objeto fundamental da análise linguística. $\mathrm{O}$ estudo dos processos 
de categorização no léxico é tomado como ponto de partida metodológico para o estudo dos processos de categorização na gramática; consequentemente, a gramática, tal como o léxico, é concebida como um inventário de unidades simbólicas (significativas).

De acordo com os significados encontrados para cada item polissêmico do conceito abstrato de AUTONOMIA, tomado aqui como exemplo, observa-se que não há um significado fixo de sentido em cada lexema. É possível encontrar muitas ocorrências polissêmicas de uso, permitindo aos TILSP realizarem escolhas de acordo com seu conhecimento especializado e linguístico.

\section{Análise do corpus: o caso das Sessões Ordinárias das Casas Legislativas}

A análise realizada de forma ilustrativa (Ver Quadro 1), neste artigo, faz parte de um corpus maior, constituído de 3 a 4 horas de Sessões Ordinárias dos Parlamentares do Brasil. Os vídeos selecionados, cobrindo o período de março a junho de 2015, foram gravados pelos Canais das TV's Câmaras que capturam as sessões ordinárias das Casas Legislativas e, depois, são disponibilizados no Youtube na Web. Essas sessões ordinárias possibilitam a comunicação acessível na presença do TILSP que realiza a interpretação simultânea do discurso de Vereadores, Deputados Estaduais e Deputados Federais. De acordo com Nascimento (2011, p. 70):

A portaria 310 de 27 de junho de 2006 do Ministério das Comunicações aponta recursos de acessibilidade na televisão para pessoas com deficiência visual e auditiva, dentre os quais se encontra o TILSP que é considerado canal de mediação entre surdos e ouvintes. A norma de acessibilidade na televisão - NBR 15.290 - estabelecida pela Associação Brasileira de Normas Técnicas (ABNT) estabelece 
parâmetros técnicos para a captação e edição da imagem do TILSP, porém os aspectos da prática interpretativa na esfera televisiva, e nos diferentes gêneros que compõem essa esfera, não são abordados nesses documentos necessitando de olhares e pesquisas que delineiem a prática do TILSP, contribuindo para a formação de profissionais que atuem nesse campo.

Para o corpus maior, selecionaram-se três vídeos das Casas Legislativas no âmbito Municipal, Estadual e Federal: (a) 22"' (minutos) da Câmara dos Deputados Federais (BSB); (b) 20" da Assembleia Legislativa do Estado do Ceará (CE); e, (c) 19" da Câmara Municipal de Pelotas. Todos se encontram disponíveis publicamente no youtube da web (Internet). Os vídeos foram salvos digitalmente para realizar uma amostra a partir da qual foi formado o corpus da pesquisa original. Foi realizado o download de cada vídeo, formando-se um banco de vídeos categorizado de acordo com cada esfera parlamentar: Municipal, Estadual e Federal. Em seguida, foi realizada a transcrição integral da fala dos parlamentares, mantendo-se a pronúncia o mais próxima possível da fala, as repetições, os alongamentos de vogais (:::), as pausas, etc. Em seguida, sincronizadas com essas falas, foram transcritas as sinalizações dos TILSP, que atuam nas "janelas de Libras" cedidas ${ }^{6}$ pelas determinações técnicas ideais apresentadas na NBR 15.290 da Associação Brasileira de Normas Técnicas (ABNT).

Dentre os softwares disponíveis, escolheu-se para esta análise o ELAN que permite "inserir vocabulário controlado, tipos lingüísticos [e] trilhas de transcrição”. Para Quadros e Pizzio (2009, p. 23), "[a] primeira coisa que deve ser feita ao iniciar um documento [...] no ELAN é definir quais as trilhas de transcrição que serão necessárias para um determinado projeto [...] determinar o tipo lingüístico que [vai] aplicar a cada trilha de transcrição [...]”. Sendo assim, as trilhas utilizadas para a transcrição do corpus dessa pesquisa, foram duas: (1) LP.ORAL - Língua Portuguesa na modalidade oral - transcrita entre aspas duplas (“...”), letras minúsculas 
e itálico; e, (2) LIBRAS.TILSP - Língua Brasileira de Sinais da atuação do Tradutor e Intérprete de Libras e Português - transcrita entre colchetes angulados $(<>)$ e letras com fonte em caixa alta ${ }^{7}$.

Para a análise do corpus neste artigo foi selecionado um recorte das transcrições da Sessão Ordinária da Tribuna Livre da Câmara Municipal de Pelotas.

A Figura 1 ilustra uma das telas do ELAN e seu sistema de anotações. Nela pode-se ter a imagem do parlamentar em plano aberto e, na janela inferior à direita, a imagem do TILSP no ato de interpretação/tradução. Para a análise, nesta seção, utiliza-se uma notação simplificada para os objetivos do presente artigo. No corpus original estão anotados os segundos de as pausas e outras referências linguísticas.

Após a transcrição na trilha da LP.ORAL, iniciou-se a transcrição das glosas interpretadas simultaneamente pelo TILSP, utilizando-se da trilha LIBRAS.TILSP, conforme a Figura 1:

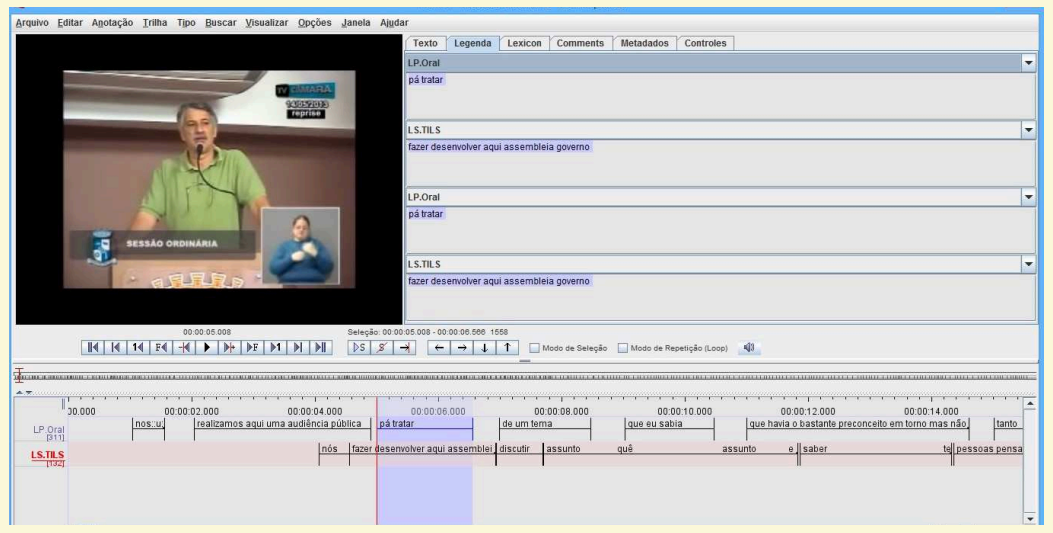

Figura 1 - Inserção das trilhas no ELAN ${ }^{8}$

Fonte: Tela do Software ELAN

No sistema de transcrição para anotações das glosas em Libras, foi necessário adicionar uma trilha que define os atributos com que se trabalhou nesse corpus ilustrativo. Essa análise focaliza os 
sinais manuais (glosas) empregados pelos TILSP para expressar as escolhas interpretativas realizadas em cada enunciado do discurso do vereador. Na trilha de anotações da LP.ORAL, foram geradas 311 sentenças capturadas do discurso do vereador. E na segunda trilha de anotações geraram-se 132 glosas capturadas pela atuação de dois TILSP que se revezavam durante o discurso do parlamentar no vídeo de duração de período de 15 minutos. As transcrições nas trilhas são compreendidas como registros que permitem ao pesquisador armazenar informações de particularidades lexicais que se apresentam a cada glosa escolhida pelo TILSP e, nesse caso, também pelo parlamentar municipal. Esse procedimento permite uma sistematização dos registros transcritos, de forma a realizar com mais precisão as análises daquilo que é objeto da investigação.

A partir da transcrição nas trilhas, realizou-se uma análise preliminar das anotações registradas da interpretação simultânea dos TILSP em comparação com o discurso realizado em LP pelo parlamentar. Na Figura 2, visualiza-se o recorte das anotações registradas em cada trilha do Sistema de Transcrição do ELAN:
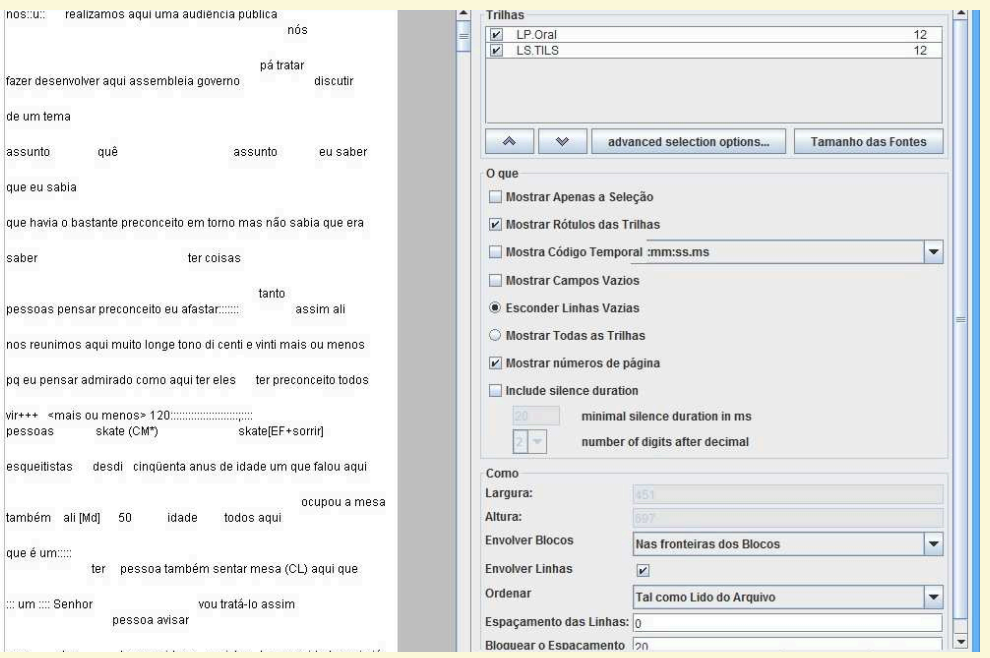

FIGURA 2 - Inserção das trilhas no ELAN

Fonte: Tela do Software ELAN 
Na Figura 3, encontra-se um exemplo de anotações de glosas as inserções linguísticas nas trilhas do ELAN:

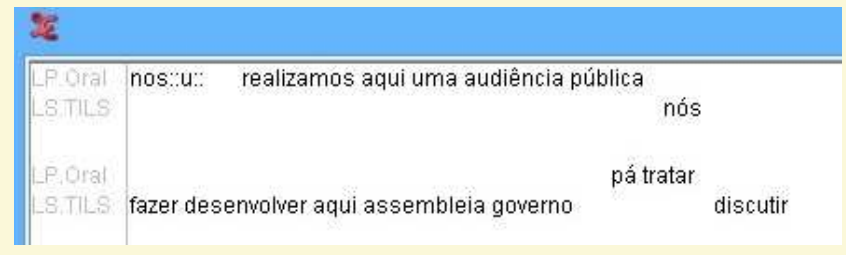

FIGURA 3 - Inserção das trilhas no ELAN

Fonte: Tela do Software ELAN

Nessa primeira análise, observe a trilha de transcrição da LP.ORAL registrada com a sentença do discurso do vereador "nos:::u:: realizamos aqui uma audiência pública" e analisa-se a trilha de transcrição da LIBRAS.TILSP com uma única glosa: $<$ NÓS $>$.

Na sequência das anotações a trilha de transcrições da LP.ORAL expressa "pá tratar" pelo vereador e para a trilha de transcrição da LIBRAS.TILSP as glosas anotadas foram <FAZER DESENVOLVER AQUI ASSEMBLEIA GOVERNO > e ao final da frase o TILSP em atuação complementa com a interpretação com a glosa $<$ DISCUTIR $>$.

Dando seguimento à análise do corpus do processo interpretativo simultâneo, apresenta-se no Quadro 1, o discurso do vereador (parlamentar municipal) e às escolhas interpretativas da LP para Libras: 
QUADRO 1 - Escolhas Interpretativas dos TILSP da Sessão Ordinária Câmara Municipal de Pelotas

\begin{tabular}{|c|c|c|}
\hline $\mathbf{N}^{0}$ & LP.ORAL & LIBRAS.TILSP \\
\hline 1 & $\begin{array}{cc}\text { "nos:u::: realizamos aqui } \\
\text { uma audiência pública" }\end{array}$ & \\
\hline 2 & & $\begin{array}{l}<\text { NÓS } \quad \text { FAZER DESEN- } \\
\text { VOLVER AQUI ASSEMBLEIA } \\
\text { GOVERNO > }\end{array}$ \\
\hline 3 & "pá tratar" & $<$ DISCUTIR $>$ \\
\hline 4 & "de um tema" & \\
\hline 5 & & $\begin{array}{c}\text { <ASSUNTO O QUE } \\
\text { ASSUNTO EU SABER > }\end{array}$ \\
\hline 6 & "que eu sabia” & \\
\hline 7 & $\begin{array}{l}\text { "que havia bastante preconceito em } \\
\text { torno mas não sabia que era" }\end{array}$ & [pausa] \\
\hline 8 & & $<$ SABER TER COISAS $>$ \\
\hline 9 & "Tanto" & $\begin{array}{l}<\text { PESSOAS PENSAR PRECON- } \\
\text { CEITO EU AFASTAR:::::::::::> }\end{array}$ \\
\hline 10 & & $<$ ASSIM ALI $>$ \\
\hline 11 & "nos reunimos aqui longe torno de" & $\begin{array}{l}<\text { PORQUE EU PENSAR ADMI- } \\
\text { RADO COMO AQUI TER ELES } \\
\text { TER PRECONCEITO TODOS }>\end{array}$ \\
\hline 12 & "cento e vinte mais ou menos" & $\begin{array}{c}<\text { VER }+++<\text { MAIS OU ME- } \\
\text { NOS }>120::::::::::::::: \text { PESSOAS } \\
\text { SKATE }(\mathrm{CM})>\end{array}$ \\
\hline 13 & $\begin{array}{l}\text { "desde cinquenta anos de } \\
\text { idade em que falou aqui" }\end{array}$ & [pausa] \\
\hline 14 & & $\begin{array}{l}<\text { TAMBÉM ALI [MD] } 50 \text { IDADE } \\
\text { TODOS AQUI }>\end{array}$ \\
\hline 15 & $\begin{array}{c}\text { "осирои a mesa } \\
\text { é um......." }\end{array}$ & $\begin{array}{l}<\text { TER PESSOA TAMBÉM SEN- } \\
\text { TAR MESA (CL) AQUI O QUÊ > }\end{array}$ \\
\hline 16 & ":::um:::: senhor" & [pausa] \\
\hline 17 & & $<$ PESSOA AVISAR $>$ \\
\hline 18 & "vou tratá-lo assim" & $\begin{array}{c}<\text { QUE TER HOMEM IDO- } \\
\text { SO AQUI TER HOMEM IDADE } \\
\text { MAIS JÁ TER }>\end{array}$ \\
\hline
\end{tabular}




\begin{tabular}{|l|c|c|}
\hline 19 & $\begin{array}{c}\text { "que já foi o secretário municipal } \\
\text { de transporte e trânsito a cidade } \\
\text { que é hoje" }\end{array}$ & \\
\hline $\mathbf{2 0}$ & & $\begin{array}{c}\text { <JÁ TER PASSADO SECRETA- } \\
\text { RIA <CARRO+TRÂNSITO > } \\
\text { AQUI CIDADE > }\end{array}$ \\
\hline $\mathbf{2 1}$ & $\begin{array}{c}\text { "é empresário no ramo de combus- } \\
\text { tíveis" }\end{array}$ & $\begin{array}{c}\text { <AGORA/HOJE TRA- } \\
\text { BALHO EMPRESA ÁREA } \\
\text { [GASOLINA+POSTO] AQUI> }>\end{array}$ \\
\hline $\mathbf{2 2}$ & "é o que falta" & <HOMEM ADVOGADO SKATE \\
\hline $\mathbf{2 3}$ & "um advogado" & FALOU QUE AQUI TAMBÉM \\
& & CONATE > \\
\hline $\mathbf{2 4}$ & continua (...) & \\
\hline
\end{tabular}

Analisando os segmentos apresentados no Quadro 1, percebese que o TILSP, na linha 1 da coluna LP.TILSP, ao receber o retrospecto vocal do discurso do vereador, realizou a escolha interpretativa para <ASSEMBLEIA GOVERNO> quando o mesmo expressa o conceito de AUDIÊNCIA PÚBLICA. De acordo com Nascimento (2011, p. 70):

[o] TILSP, por sua vez, sendo o profissional apontado pela legislação como a ponte de acesso dos surdos à informação veiculada na esfera televisiva, deve [ater-se] à variedade de gêneros discursivos que circulam nessa esfera atentando-se para as peculiaridades de cada um, analisando a totalidade verbo-visual, considerando os aspectos linguísticos e extralinguísticos, que influenciam e/ou interferem no processo tradutório/interpretativo. No entanto, para que todos esses aspectos sejam considerados pelo TILSP no ato tradutório/ interpretativo, faz-se necessário uma formação que abranja esses aspectos, além de outros, para a construção de uma prática efetiva.

Refletindo sobre as considerações do autor, podemos destacar a necessidade de o TILSP valer-se também de um conhecimento 
especializado. Nesse sentido, as "inserções deste profissional e da variedade estilística das produções audiovisuais, reafirmamos que o intérprete é um agente de acessibilidade para que telespectadores surdos tenham acesso aos conteúdos produzidos na mídia televisiva" (NASCIMENTO, 2011, p. 80). Para essa acessibilidade aos telespectadores surdos, precisa-se adentrar nas implicações referentes à interpretação simultânea que os TILSP realizam em relação às escolhas que afetam a compreensão desse telespectador surdo. Porém, em se tratando de uma interpretação em mídia aberta, o TILSP não tem como perfilar seu interlocutor. Esse pode ser um sujeito surdo com formação superior ou com pouca formação escolar. Portanto, o fato de o TILSP estar se dirigindo para um público heterogêneo, leva-nos a refletir sobre as escolhas interpretativas realizadas para o conceito de AUDIÊNCIA PÚBLICA. Hipoteticamente, colocamos o TILSP numa situação em que o mesmo tenha tido um conhecimento prévio do enunciado da LF e ele interpretasse o conceito de AUDIÊNCIA PÚBLICA com as seguintes glosas: <IMPORTANTE REUNIÃO PÚBLICO+SOCIEDADE FAZER [AQUI $\left.{ }^{\circ}\right]>$ ou uma outra opção de escolha interpretativa: $<$ REUNIÃO DIVULGAR POPULAÇÃO PARTICIPAR > e entre outras possíveis escolhas. As possibilidades interpretativas para o conceito de AUDIÊNCIA PÚBLICA são variadas, mas o TILSP, no uso de suas competências e em função de seu compromisso social, deveria estar atento para uma interpretação que alcançasse o maior número de sujeitos da comunidade surda.

Nas linhas 7 do Quadro 1 o vereador na LP.ORAL enuncia "que havia bastante preconceito em torno mas não sabia que era (pausa) tanto" e o TILSP interpreta que < PESSOAS PENSAR PRECONCEITO EU (sustentou o sinal $<$ EU $>$ ) AFASTAR::: ${ }^{10}>$. Observa-se que TILSP, por sua vez, realizou as escolhas adequadas para aquele momento de interpretação simultânea, porém, acrescentou uma expressão nas glosas. Com relação a isso, caberia uma reflexão sobre os motivos que levaram o TILSP a realizar esse acréscimo em suas escolhas interpretativas, quando não há, no enunciado do locutor, referências no sentido de AFASTAR. Também, perce- 
beu-se que TILSP não compreendeu o áudio do enunciado quando mencionou a expressão "tanto" ou seu conhecimento empírico em relação ao lexema 'tanto' tem o sentido de EU AFASTAR. A expressão "tanto", nesse contexto, significaria o sentido de UMA GRANDE QUANTIDADE, ou seja, é MUITO PRECONCEITO com relação às pessoas referidas naquele enunciado. Observa-se que, diferentemente de 'audiência pública', que é uma expressão mais técnica, 'tanto' faz parte de um vocabulário cotidiano dos falantes-ouvintes. Veja-se que 'tanto' também é um item lexical polissêmico e pode estar presente em construções do tipo 'tanto isso, como aquilo' ou 'tanto um, como o outro', ambas construções inclusivas; mas tem-se, também, 'tanto debate' significando TODO ESSE DEBATE; e, no caso em questão, "tanto [preconceito]", significaria, como se afirmou anteriormente, algo na dimensão do TAMANHO ou QUANTIDADE [DE PRECONCEITO].

Continuando a análise, observa-se também que na linha 15 do Quadro 1, o locutor usa a expressão "mesa”, e o TILSP interpreta $<$ SENTAR MESA > . O lexema 'mesa', no contexto político, remete à MESA DIRETORA, ou seja, aos representantes legais (da mesa diretora) de uma Casa Legislativa. Analisando essa escolha do TILSP, observa-se que este apenas buscou uma alternativa que explora 'aqui' como um dêitico para 'Casa Legislativa'. O item lexical 'mesa' também é polissêmico e, no contexto pragmático de fala, metonimicamente refere os membros que compõem a diretoria daquela sessão. Ou seja, não se trata de 'mesa', no sentido de peça do mobiliário, mas dos membros que constituem um corpo diretivo e que se posicionam, de uma dada maneira, na mesa que coordena às atividades, nesse caso em específico.

Nas linhas 16 a 18, encontramos a enunciação do parlamentar proferido como "um senhor"/ "vou tratá-lo assim" e na respectiva versão do TILSP as glosas interpretadas como < PESSOA AVISAR/QUE TER HOMEM IDOSO AQUI TER HOMEM IDADE MAIS JÁ TER $>$. Não se trata, aqui, de uma terminologia de contexto político, mas de construções presentes na linguagem cotidiana. A expressão "senhor", como se verá na sequência da 
análise, refere-se a uma designação que provavelmente está sendo utilizada em tom irônico ( "vou tratá-lo assim" [polidamente, para não tratá-lo de outro modo]). O TILSP escolhe uma construção que apaga essa designação, além de acrescentar < PESSOA AVISAR QUE TER HOMEM IDOSO > // < TER HOMEM IDADE MAIS [...]> ". Entretanto, "senhor" está sendo utilizado como forma de tratamento apenas e não para designar idade avançada. Os demais acréscimos, além de não serem adequados, não cobrem o sentido pretendido pelo locutor. Além disso, não há como saber a razão do acréscimo $<$ PESSOA AVISAR $>$. Na fala do parlamentar, tratase apenas de uma referência que antecede um segmento que terá "senhor" como uma designação, conforme referido anteriormente, e não há, portanto, conotação de AVISO nessa menção.

Na sequência das análises, observa-se que nas linhas 19 e 21 do Quadro 1, o locutor expressou "secretário municipal", e o TILSP sinaliza para a "Secretaria Municipal de Transporte e Trânsito", ou seja, faz uso de outros sentidos para a interpretação em Libras, usando as glosas como < SECRETARIA [CARRO+TRÂNSITO] AQUI CIDADE $>$. Observa-se, nesse momento, que foi omitida a expressão "transporte", interpretado, possivelmente, como $<$ CARRO $>$, o que carrega o sentido de um tipo de meio de transporte; "secretário" foi substituído por <SECRETARIA $>$; e "municipal" foi sinalizado como <AQUI CIDADE $>$. Essas escolhas interpretativas estão carregadas de omissões e substituições. A interpretação é compreensível. Porém, não se pode deixar de observar que a referência é "secretário municipal de transporte e trânsito" e não o setor, ou seja, a "secretaria". Portanto, não é dado a conhecer o cargo daquele que, como afirmado na linha 21 , também é empresário do ramo de transportes.

Primeiramente, os conceitos de TRANSPORTE (como hiperônimo) e TRÂNSITO podem fazer parte do mesmo campo conceitual, mas seus significados não se sobrepõem no contexto específico da enunciação referida. Desse modo, substituir o conceito TRÂNSITO pelo de CARRO não é adequado, embora, em outros contextos, essa substituição pudesse servir aos propósitos da comu- 
nicação. Em segundo lugar, o que deve ser inferido na enunciação do parlamentar é o possível conflito de interesses que se estabelece entre o cargo exercido por uma pessoa ("secretário") e a outra função exercida ("empresário do ramo de combustíveis"). Esse conflito deixa de existir com a substituição de "secretário" por $<$ SECRETARIA > , já que a secretaria não pode ter, de maneira inequívoca, uma conexão com "um empresário". Os conceitos de SECRETÁRIO e SECRETARIA são diferentes e podem, nesse contexto, interferir na compreensão do pronunciamento. Não se trata de uma conexão trivial, mas crucial para o entendimento do que está efetivamente em jogo na fala do parlamentar. Em terceiro lugar, a escolha por < AQUI CIDADE > para "Municipal” é uma opção por [dêitico + sinônimo], em que a composição remete à cidade de Pelotas, e o dêitico a referindo-se a ESTA CIDADE. Não havendo um equivalente lexemático para o sentido de MUNICIPAL nas escolhas interpretativas para Libras, a escolha é aceitável. Porém, alerta-se que em outros contextos, na referência a outros "municípios" ou numa referência ao âmbito "Municipal", sem quaisquer outras especificações, perder-se-ia a extensão a que o conceito se refere.

Como se pode observar nessa breve ilustração que serve a nossas reflexões, as escolhas lexemáticas nas traduções simultâneas envolvem decisões muito rápidas na busca de sentidos congruentes. Algumas paráfrases podem interferir na compreensão do telespectador, seja esse limitando o sentido pretendido pelo falante de LP, seja esse distorcendo o sentido comunicado em LP. Entende-se que a polissemia está presente tanto nas construções em LP como no léxico de Libras. Compreende-se que na natureza enciclopédica do significado, determina vários domínios da experiência humana, conceptualizando os diferentes domínios semânticos (SILVA, 2003). No caso da terminologia política, há especificidades que não podem ser negligenciadas, suscitando uma formação setorizada para o TILSP, ou seja, definindo uma formação por área de atuação. E por fim, observa-se, na linha 22, que o TILSP omitiu a informação que o locutor enunciou verbalmente, ou seja, no ato 
interpretativo não houve ocorrências explícitas que referenciassem a expressão "é o que falta" durante a interpretação simultânea da sentença em LP. Observando a sequência, verifica-se que se trata de um deslocamento. A construção seria "um advogado é o que falta", ou seja, o locutor indica que, para o caso do conflito de interesses, é necessária a intervenção de um advogado. A não sinalização desse fechamento na fala do locutor deixa incompleta sua proposição. Cabem aqui as colocações de Barbosa (2014, p. 106) sobre a questão das omissões em seu estudo:

identificamos ainda [na pesquisa] que nem sempre elas [as omissões] foram utilizadas como uma estratégia para tornar a interpretação mais eficaz, mas, são o resultado do enfrentamento do intérprete com as demandas que surgiram no decorrer do processo e, por eles não estarem preparados para esse confronto, intérprete versus demanda, a consequência foi a omissão. Observamos também que o intérprete atua com a sua capacidade cognitiva [ao] máximo e que o surgimento de qualquer demanda que exija maior capacidade cognitiva poderá afetar o processo interpretativo, desencadeando falhas ou equívocos nas decisões do intérprete, mesmo que de forma inconsciente [...].

A partir dessa breve ilustração, podemos afirmar que as escolhas lexicais para a interpretação simultânea são escolhas rápidas que acontecem com base em todo o conjunto de enunciados anteriormente pronunciados de acordo com todos os aspectos situacionais que os significam, ou seja, informações obtidas na língua de partida, traduzidas cognitivamente, e interpretadas para a língua de chegada, em que fatores linguísticos, contextuais e culturais concorrem para o êxito da interpretação.

Esse processo, segundo Machado (2012, p. 178), quando exitoso, ocorre quando as competências linguísticas e tradutórias desenvolvidas pelos TILSP no ato interpretativo são adequadas, ou seja, quando 
a. envolve a posição e a postura que o TILSP assume no ato do momento da interpretação;

b. referencia os sujeitos do discurso durante o ato da interpretação;

c. armazena as informações do enunciado na memória de trabalho;

d. incorpora na ação o sujeito do discurso quando necessário;

e. resgata pistas metalinguísticas durante suas escolhas de lexemas numa construção lexemática;

f. tem o domínio e o autocontrole linguístico em situações que o TILSP não possui conhecimentos prévios de contexto, de discurso e de posicionamento (cenário) em uma situação de interpretação simultânea;

g. trabalha em parceria com um ou mais colegas de atuação, ou seja, trabalha com interpretação de apoio;

h. mantém-se alinhado ao enunciado e ao contexto de atuação; e,

i. transmite as informações que ocorrerem no ato de fala, atentando para a percepção linguística-visual, no que tange aos aspectos gramaticais da Libras e o conhecimento linguístico, ou seja, a capacidade de interpretação da língua fonte para a língua meta.

Essas são algumas das competências e habilidades que o TILSP deve continuamente desenvolver em sua atividade de grande responsabilidade social diante da comunidade surda. O significado das palavras está subordinado aos frames mentais e, dessa maneira, a interpretação de um conceito/item lexical requer o acesso às estruturas de conhecimentos que se relacionam com elementos e entidades associados às cenas da experiência humana, consideradas como bases físicas e culturais dos processos cognitivos.

Mesmo por meio de uma análise ainda parcial e seletiva, verifica-se que não só conceitos abstratos são, de fato, problemáticos tanto para os TILSP como para os sujeitos surdos, mas também os itens lexicais de seu uso no cotidiano. Consideram-se os casos 
que são possíveis variadas escolhas passíveis de realização num ato interpretativo, ou seja, O TILSP procura sinônimos aproximados ou constrói paráfrases para que os significados em LP sejam compreendidas pelo sujeito surdo. Essas escolhas ora se ajustam, em algum grau, ao significado contextual, ora se distanciam, em cada versão.

\section{Considerações Finais}

A intenção deste artigo ensaia os primeiros passos para tentar contribuir para aspectos fundamentais da competência tradutória, especificamente nas particularidades da tradução e interpretação em contexto político. Ao focalizarmos as questões semântico-pragmáticas das problemáticas relativas aos conceitos abstratos, amplia-se o corpus de pesquisas no âmbito do conhecimento especializado na competência interpretativa de LP para Libras nesse contexto específico.

A função do TILSP vai muito além da mera ação de gesticular ou apontar o concreto. Percebe-se que o TILSP assume a figura de mediador situacional. A questão da interpretação pode ser problemática na interpretação simultânea, pois são tomadas decisões encadeadas, de forma contínua, num período de tempo bastante exíguo, quanto à possível utilização de um conjunto de signos, construções gramaticais e culturais por parte do TILSP ao interpretar.

A análise realizada visa apenas a uma reflexão sobre as escolhas interpretativas do TILSP, não tendo em seu escopo examinar como os sujeitos surdos compreendem as interpretações elegidas. Para tanto, seria necessário empreender um estudo empírico com outros métodos, instrumentos e procedimentos apropriados.

Assim, é a partir de uma tensão experimental que essa prática opera, num sentido que visa tanto à manifestação como à construção de um lexema manual capaz de gerar um significado cultural de compreensão pela procura do sentido do enunciado, que está "contido" nas expressões mediadas simbolicamente. Dessa manei- 
ra, encontra-se no ato interpretativo o movimento de sentidos, que é característico da construção de significados semântico-pragmáticos em variados contextos.

\section{Notas}

1. PACTE - Procesos de Adquisición de la Competencia Traductora y Evaluación - Universidade Autônoma de Barcelona. Disponível em: http: //grupsderecerca.uab.cat/pacte/en.

2. Entende-se o conhecimento enciclopédico como incluindo o conhecimento especializado.

3. Sessão Ordinária da Legislatura do Grande Expediente dos parlamentares.

4. "Segundo o censo demográfico efetuado pelo Instituto Brasileiro de Geografia e Estatística - IBGE no ano 2000, correspondem a 14,7\% da população nacional. Desse total, aproximadamente, seis milhões de pessoas possuem limitações parciais e/ou totais da audição". (NASCIMENTO, 2011, p. 67).

5. Nas análises, utilizam-se, aspas duplas e itálico para referir as expressões enunciadas pelo parlamentar, aspas simples para referir a itens ou construções lexicais e caixa alta para referir a conceitos. Trata-se de uma notação usual nas análises linguísticas.

6. Vídeo retirado do Canal do Youtube da Câmara Municipal dos Vereadores de Pelotas. Disponível em: https://www.youtube.com/watch?v=y_jBJOpAZX8.

7. O TILSP poderá realizar o sinal manual que é usado na região de Pelotas pela comunidade surda. Esse sinal manual representa o sentido de <CÂMARA MUNICIPAL DOS VEREADORES DE PELOTAS $>$. 
8. Os dois pontos apresentados diversas vezes na trilha significa que o locutor sustentou a vogal ou a consoante por alguns segundos.

\section{Referências}

ALVES, Fábio. Ritmo cognitivo, meta-reflexão e experiência: parâmetros de análise processual no desempenho de tradutores novatos e experientes. In: PAGANO, Adriana; MAGALHÃES, Célia; ALVES, Fabio (Org.). Competência em tradução: cognição e discurso. Belo Horizonte: Editora UFMG, 2005. p. 109-153.

ARROJO, Rosemary. Oficina da tradução: a teoria na prática. 5. Ed. São Paulo: Ática, 2007.

BARBOSA, Diego M.. Omissões na interpretação simultânea de conferência: língua portuguesa - língua brasileira de sinais. Mestrado Estudos da Tradução (Dissertação de Mestrado). Florianópolis. PGET/UFSC. 2014.

BASSNETT, Susan. Estudos da tradução. Porto Alegre: Editora da UFRGS, 2005.

BRASIL. Lei $n^{o}$ 10.436, de 24 de abril de 2002. Dispõe sobre a Língua Brasileira de Sinais - Libras e dá outras providências. Disponível em: < http://www. planalto.gov.br/CCIVIL/LEIS/2002/L10436.htm > . Acesso em: 20 abr. 2015.

BRASIL. Decreto $n^{\circ} 5.626$, de 22 de dezembro de 2005. Regulamenta a Lei $\mathrm{n}^{\circ}$ 10.436, de 24 de abril de 2002, que dispõe sobre a Língua Brasileira de Sinais Libras, e o art. 18 da Lei ${ }^{\circ} 10.098$, de 19 de dezembro de 2000. Disponível em: < http://www.planalto.gov.br/CCIVIL/_Ato2004-2006/2005/Decreto/D5626. htm >. Acesso em: 20 abr. 2015.

DASCAL, Marcelo. Interpretação e compreensão. São Leopoldo, RS: Editora Unisinos, 2006. 
DELBECQUE, N. Linguística cognitiva: compreender como funciona a linguagem. Lisboa: Instituto Piaget, 2008.

ECO, Umberto. Quase a mesma coisa: experiências de tradução. Tradução de Eliana Aguiar. Rio de Janeiro: BestBolso, 2011.

EVANS, Vyvyan. How words mean: Lexical concepts, cognitive models and meaning construction. New York: Oxford University Press, 2009.

HURTADO ALBIR, Amparo. Enseñar a traducir: metodologia em La formación de traductores e intérpretes. Col. Investigación didáctica, Madrid: Edelsa. Grupo Didascalia S.A, 1999.

HURTADO ALBIR, Amparo. A aquisição da competência tradutória: Aspectos teóricos e didáticos. In: PAGANO, Adriana; MAGALHÃES, Célia; ALVES, Fabio (Org.). Competência em tradução: cognição e discurso. Belo Horizonte: Editora UFMG, 2005. p. 19-57.

JAKOBSON, R. Linguística e comunicação. 8. Ed. São Paulo: Cultrix, 1975

LACERDA, Cristina B. F.. Intérprete de Libras: em atuação na educação infantil e ensino fundamental. 2. Ed.. Porto Alegre: Mediação, 2010.

MACHADO, Flávia M. A. Interpretação e Tradução de Libras/Português/Libras dos Conceitos Abstratos CRITICO e AUTONOMIA. (Dissertação de Mestrado). Caxias do Sul - RS. UCS/PPGLET, 2012.

NASCIMENTO, Marcus Vinícius Batista. Interpretação da língua brasileira de sinais a partir do gênero jornalístico televisivo: elementos verbo-visuais na produção de sentidos. (Dissertação de Mestrado). São Paulo - SP. LAEL/PUC-SP, 2011.

OUSTINOFF, Michaël. Tradução: história, teorias e métodos. São Paulo: Parábola Editorial, 2011.

QUADROS, Ronice Müller de. O tradutor e intérprete de língua de sinais brasileira e língua portuguesa. Secretaria de Educação Especial; Programa Nacional de Apoio à Educação de Surdos. Brasília: MEC, 2002. 
QUADROS, R. M. de; PIZZIO, A. L. Língua Brasileira de Sinais IV. Curso de graduação de Letras Libras. CCE/UFSC, 2009.

SACKS, Oliver. Vendo vozes: uma jornada pelo mundo dos surdos. Rio de Janeiro, Imago Editora, 2002.

SILVA, Augusto S. da.. O mundo dos sentidos em português: polissemia, semântica e cognição. Coimbra: Almedina, 2006.

SILVA, Augusto S. da. O Sentido múltiplo: polissemia, semântica e cognição. In.: FELTES, Heloísa Pedroso de Moraes. Produção de Sentidos: estudos transdisciplinares. São Paulo: Annablume; POA: Nova Prova; Caxias do Sul: Educs, 2003. p. 91-115.

SILVA, Augusto S. da. Polissemia e contexto: o problema duro da diferenciação de sentidos. IN.: Estudos Linguísticos/Linguistic Studies. 5. Ed. Colibri/CLUNL. Lisboa, 2010. p. 353-367.

RÓNAI, Paulo. Escola de tradutores. Rio de Janeiro: Educom, 1976.

RÓNAI, Paulo. A tradução vivida. Rio de Janeiro: Educom, 1976.

Recebido em: 30/06/2015 Aceito em: 30/09/2015 